\title{
Reading Foucault: Genealogy and Social Science Research Methodology and Ethics
}

\author{
by Wendy Bastalich \\ University of South Australia \\ Sociological Research Online, Volume 14, Issue 2, \\ $<$ http://umw. socresonline.org.uk/14/2/3.html> \\ doi:10.5153/sro. 1905
}

Received: 2 Apr 2009 Accepted: 6 May 2009 Published: 30 May 2009

\begin{abstract}
Foucault's work has given rise to increased methodological sensitivity of the political dangers associated with traditional qualitative approaches in the social sciences. There is a growing awareness that the widespread use of the research interview is not indicative of a deepening insight into the workings of culture, but is part of a broader social technology for its reproduction. In an effort to re-imagine interview methodology, scholars have read Foucault to suggest the need for greater attention to the active coconstruction of research conclusions arising from interview based research. This has led in turn to the view that post modern approaches produce localized, temporally specific knowledge that fails to shed light on deeper, more enduring social structures. This paper questions these interpretations of Foucault's work, arguing that they fail to accurately represent his genealogical method or to consider its implications for research ethics. Foucault rejects a view of knowledge as emerging from the active social constructions of agents or of institutionalised 'interests'. Rather, Foucault sees knowledge as an outcome, often accidental, of interrelated historical practices and discourses that produce the subjects and objects of social science discourse itself. The implications of Foucault's work for thinking about research ethics is not a return to authenticity or to analyses of social structure, but a rejection of the centralised, regulatory claims of an organised scientific discourse. The paper comprises a review of social science responses to post structural insights, coverage of the critical epistemological differences between Foucault's method and other key social theory paradigms, and a discussion of the critical ethical issues these differences raise for the social sciences.
\end{abstract}

\section{Keywords: Social Sciences, Methodology, Research Ethics, Research Epistemology, Foucault, Qualitative Methodology}

\section{Introduction}

1.1 Post modern challenges to foundationalism, including those of Michel Foucault, have sparked renewed discussion about traditional qualitative research methods among social scientists. Foucault's work on the spread of confessional practices has given rise to an increased sensitivity to the possibility that the ubiquity of the interview in modern society 'ramifies the very culture it ostensibly only inquires about' (Gubrium and Holstein, 2003:47). In reading Foucault to find a way out of this dilemma a 'new' understanding of the interview has arisen which sees it as a technology that 'not only produces data but simultaneously constructs individual and public opinion' (Gubrium and Holstein 2003:30). Foucault's work is drawn upon to emphasise the active role of the researcher in constructing the final representations that are distilled from data (Gubrium and Holstein 2003). The central ethical issue confronting researchers in this view is the overshadowing of interviewee authenticity by the idiosyncratic biases, subject positions, and disciplinary concerns of the researcher. May (2002:3) observes that the problem with the 'post modern' emphasis upon the interpreted nature of reality is that it reinstates the same subject post modernism aims to destabilise. It also renders representation 'so incoherent that engagement is difficult if not impossible, for the purposes of illuminating the dynamics of social issues' (May 2002:3). May argues for a return to representation within a critical realist and hermeneutic epistemological framework. In effect, the original dilemma that Foucault and others raise for the social sciences, and its implications for research methodology and ethics, is set aside altogether.

1.2 This paper offers an alternative reading of the implications of Foucault's work for research methodology and ethics. The paper demonstrates that Foucault's genealogical work moves away from conceptions of 
persons as meaning makers, and points instead to the role of historical practices and discourse in producing subjectivity and meaning. The paper argues that in doing so Foucault offers a distinctive epistemological and ethical basis for knowledge claims that deserves attention on its own terms. These concerns do not revolve around questions of authentic voice, but of the political dangers arising from representation, giving rise to a new attention to the interrelations of bodies, practices and knowledge. While Foucault may not be for everyone, the paper seeks to demonstrate that his approach cannot meaningfully be subsumed within constructionist or Critical research epistemologies.

1.3 The paper opens with a brief extrapolation of modernist interpretations of Foucault's approach, loosely, constructivist, social constructionist, and Critical theory approaches to qualitative methodology. This is followed with a comparison of Foucault's approach with modernist social theory paradigms highlighting how they differ in their epistemological aims. The final part of the paper contrasts Foucault's approach to research ethics with prevailing modernist perspectives and considers the key implications of Foucault's take on ethics for social researchers.

\section{Modernist readings of Foucault}

2.1 Three broad positions on the implications of 'post modernism' for social research methodology are queried in the paper. In the first, constructivist take, post modernism is read to emphasise the situational co-construction of interview data by researchers and interviewees, with the conclusion that generalised explanations should be replaced with recognition of the fragmented nature of culture (Rosenblatt, 2003; Fontana, 2003). Post modern social theory is read to suggest that the research interview reflects 'multiple intentions and desires' of researchers and of research participants (Scheurich, 1997:62). In this view, 'post modern' approaches, among which the work of Foucault is often cited, recognise the 'persistently slippery, unstable, and ambiguous' nature of language which changes from 'person to person, situation to situation, and time to time' (Scheurich, 1997:62). Rather than reject the research interview altogether as 'a mirror reflection of the researcher and her/his baggage', it can be redeemed by a 'reasonably comprehensive statement of the (researcher's) disciplinary training, epistemological orientation, social positionality, institutional imperatives, and funding sources and requirements ... so that the reader has some sense of what the researcher brings to the research enterprise' (Scheurich, 1997:74-75). Researchers should also disclose the 'shifting openness and indeterminacy' of the interview and ambiguity in the interpretation of data (Scheurich, 1997:74-75). This representation of the implications of post modern thought for research interviewing has, understandably, and unfortunately, led to the view that it makes generalisation about social issues impossible and is of little use to social researchers, since one interpretation is, apparently, just as good as another (Porter, 2002:59).

2.2 A second stream of 'post modern' commentary on the research interview emphasises the social and cultural lenses that determine what stories are produced within interviews. There is still concern about the situational and interactive co-construction of interview data by researchers and interviewees, and of the multiple subject positions available to them in negotiating what stories are told in the interview. But concern about the distinctiveness of each interview situation is replaced with an interest in its storied nature or 'narrative logic' (see for example Denzin, 2001). The emphasis here is the shared social or cultural underpinnings of subject positions like 'mother', 'researcher', 'professional', or 'addict' (see for example Gubrium and Holstein, 2003:37). This paradigm is less concerned that the perspectives of individual researchers will drive the findings, than that socially given subject positions will be reproduced within the research and that opportunities to provide openings for new ways of being will be missed. This is to be avoided by tapping into the creative, performative nature of everyday talk; 'narrative as a political act' (Denzin, 2001:43). The methodological aim is not to determine whether the representation is true, but to 'understand how people enact and construct meaning in their daily lives', to use social science to empower others, and to 'fashion performance texts that imagine new worlds' (Denzin, 2001:43). Narrative and identity are seen as told through culture, and not therefore as wildly 'indeterminate', as for constructivists. The themes that make a particular experience distinctive are seen to be generalisable to similar social situations or subject positions. The focus for social constructionism is not so much the fragmentation of culture, but distinguishing between 'new worlds' and socially given subject positions within everyday talk. What is not addressed is the methodological means by which the researcher will distinguish between what is 'original' and what is a rewrap of existing cultural points of view. In the end, despite references to Foucault and post modernism, the approach looks much like traditional social constructionism. The expert provokes and sifts through the self-revelations of research participants to determine what they 'really' mean or what constitutes a 'fresh' approach.

2.3 A third modernist approach to qualitative analysis is offered by Frankfurt School critical theory, critical realism and hermeneutic ethnographic thought. Within this broad grouping, theorists often conflate 'post modernism' and constructionist approaches arguing both are 'trapped within descending interpretative circles' (May 2002:3). Rather than shedding new light on the implications of post modern approaches to 
research methodology, this position simply restates traditional Critical critiques of social constructionism. Critical theory has long accused social constructionism of uncritically producing localized, temporally specific, subjective knowledge in which all points of view are seen as equally valid, thereby failing to reflect on the deeper, more enduring social structures or relations that produce interpretation.

2.4 For Critical and hermeneutic thinkers authors bring implicit meanings and intentions they may not themselves recognize. In critical realism and Critical theory this is overcome by reading experience through a theoretical lens which conceptualizes society as comprised of social structures or interests in which some groups wield power over others typically via ideological obscurations of class, gender and race relations. Hermeneutic or ethnographic approaches attempt to understand what is beyond consciousness via the 'hermeneutic circle' in which the ideas and terms that explain a phenomenon are read in relation to wider social relations in a cyclical process. The interpreter moves from the text or from an experience back out to the social world within which it is situated 'mapping' that world and the meaning of the text or experience within it (Smith 2002). Although not claiming to offer a representation that is beyond culture, the researcher in this epistemological paradigm aims to reveal 'hidden' structural or systemic social relations. In essence, the social scientist informed by a social scientific methodological approach, sifts the data to distinguish between the ideological and the 'socially significant'.

2.5 For Foucault, both constructionist and Critical hermeneutic paradigms are limited as a means for reflection upon society and culture because neither can shed light on the history of social practices that produce everyday meaning. Although Foucault would no doubt agree that people, including social researchers, are misled about the political origins and implications of their beliefs, it is not that they do not know what they mean in the sense that a deeper level of consciousness lays hidden from them that might be revealed by an expert social scientist. Nor is it that meaning is unimportant for Foucault, on the contrary, he was deeply concerned with the dangers and harms that arise from meaning and the social practices within which they are embedded ${ }^{[1]}$. For Foucault, what it is possible to say at a particular time and place, from a particular subject position, is given by a history of practices, and carries a series of potentially harmful effects that are beyond the feelings, perceptions and theories of those being interviewed as well as those conducting the interview.

2.6 Foucault was not convinced that hermeneutics or the Frankfurt school offer approaches capable of revealing this history of practices. Foucault (1973:333) refers to the theoretical contradictions in hermeneutics and Critical theory, which seek to show that human beings are not ultimately limited by culture in their ability to know, but are the transcendental source of history and knowledge, as 'extremely complex and extremely tangled'. For Foucault, these positions attempt to establish the grounds for positive knowledge about the social world by insisting that human consciousness is capable of observing itself from a background position that is both part of, but also transcendent to its own history. Consider Heidegger's (1967) concept of dasein, a state of interior 'being', 'presence' or 'pre-understanding' that is both in and of the world, but also somehow separate from more immediate social, cultural, and historical understandings. Similarly, Gadamer's (1975) concept 'tradition' or 'historically effected consciousness' embeds the interpreter in the past, which is carried via language, such that tradition is not something revealed by historical analysis, but by an interrogation of contemporary being. Habermas' (1984) concept of 'rational dialogue' establishes the grounds for positive, historically embedded knowledge by referring to a form of communicative competence that is seen to be unique to the human species. It is this capacity, according to Habermas, that enables inter-subjective recognition of culturally established standards of value. For Foucault, explanations emerging from these epistemologies merely recirculate existing meanings in an endless stream without providing the distance to observe the field within which they are produced. In a Foucaultian frame, the condition of contemporary society cannot be understood by examining the negotiated meanings of social agents, nor can it be found within the broader field of social relations. Rather a history of ungoverned practices and knowledge relations brings subjects and the knowledge that constitutes them into play. Foucault called the methodological approach that takes the history of these relations as its object of investigation 'genealogy'.

\section{Foucault's genealogies}

3.1 Foucault's 'genealogical method' constitutes a distinctive epistemological aim. Foucault was clear that social science knowledge cannot be legitimised on the basis of essential features of 'reality' or of the human mind (positivism, Lockean empiricism, Kantian empiricism), individual or culturally mediated interpretations of objective phenomena and events (constructivism, constructionism, interpretivism, and some forms of phenomenology), or socially constituted structures, relations or processes (Frankfurt School Critical theory, critical realism, hermeneutics). This does not however prevent Foucault from offering generalised comment on the condition of contemporary Western culture. Indeed his work on the contemporary era emphasises not multiplicity, flux or cultural interpretation, but an increased and diffusely situated aspiration for order, obedience, predictability, standardisation and regulation. His work can be read 
to reveal the history of this desire for control, and its operation. In Foucault's conception, power and control are not achieved by misrepresenting more authentic realities. Power operates by the transformation of persons into objects and subjects of knowledge. The social sciences and its claims about how people really think and feel are part of the means by which subjects come into existence. The social sciences are then powerful and central in the project of social control. Before considering the ethical implications of this insight for social science research, more might be said about Foucault's key 'genealogical' studies, or rather what makes them distinctive compared to modernist paradigms.

3.2 The order of things (1973) begins Foucault's continuing exploration of the epistemological history of the human or social 'sciences', among which he investigated psychology, demography, statistics and criminology. The order of things traces the rise of the modern episteme or the methodological interest in human beings as objects of scientific knowledge, and the phenomenological and hermeneutic interest in human beings as subjects possessed of, or invested in, deep meaning. In the Order of things, Foucault observes the rise of the focus on human beings as subjects and objects of knowledge in the modern age with the gradual dawning of the realisation that human knowledge is conditioned by language and culture; forces that precede and shape consciousness and language. Foucault (1973) argues that instead of accepting the epistemological implications of this, that positive knowledge about human beings is impossible, modernism produces a set of illogical philosophical presuppositions to support its knowledge claims. The Order of Things suggests that the desire to understand human beings and their relation to society is not an inevitability of advancing knowledge, but a peculiarity of the times; a project that is logically unworkable. His later work shows how this project becomes inextricably linked to the operation of power.

3.3 The history of sexuality and Discipline and Punish trace the social and institutional practices that gradually accumulate a corpus of knowledge about human beings; including the practices of social science research. The history of sexuality (1976) traces the practice of the confession and its development of a focus on persons as subjects of knowledge, subjects who nevertheless require experts to draw out and interpret the meanings and motivations buried within them. For Foucault, this desire to know oneself and others, to conduct endless series of self-exploratory and self-revealing interviews, does not provide insight into the process by which meaning is produced but acts to render persons susceptible to new forms of intervention and control. It is not the researcher's values or perspectives that are produced within the interview process so much as prevailing cultural norms about the nature and proper conduct of persons, and the relations between particular subject positions. The history of sexuality refutes the reading of the history of sexuality as a gradual lifting of repressions, and argues that the information gleaned from the confession enabled the 'discovery' or 'implantation' in the population of a sexual 'life force' which must constantly assert its right to liberation. The book outlines how the new knowledge assembled via practices of the confession gradually becomes the means by which the population is regulated in more 'healthful' directions. Armed with knowledge of the 'nature' of human beings, governments aim to know and manage population with its phenomena and variables such as birth and death rates, life expectancy, fertility, state of health, frequency of illnesses, patterns of diet and habitation. The problems and solutions this produces form the basis for new regulations to enable the performance, monitoring, control and policing of 'healthy' sexuality and its 'normal' expression.

3.4 In Discipline and punish (1977) Foucault outlines the micro institutional practices and political imperatives that, from the $16^{\text {th }}$ century in Europe, enabled 'observations' of the 'organic' body complete with a 'natural' proclivity for the forms of training and control favoured within the institutions that emerged with industrial capital. Within prisons, the military, factories, hospitals and schools, temporal, micro-institutional practices allocate individuals to specified places and tasks in relation to other individuals. This allows tighter control and surveillance, and an increased productivity of bodies. The institutionalisation and control of bodies give rise to a mass of documentation about the relations of bodies with one another and with the spaces around them. The prevailing humanist sense that human beings are a distinctive kind of animal leads to the gradual conflation of the disciplinary observations of bodies with 'knowledge' of human beings, their propensities, limits, proclivities. In this moment the social and human sciences are born. Discipline and Punish observes the regulatory power of these new knowledges which enable interventions, both external and internal to the subject, in the name of 'natural' and 'normal' human behaviour, effectively obliging persons to conform, or be 'aberrant', 'anti-social' or 'deviant'. For Foucault, the confession cannot 'uncover' something deeper that resists the disciplinary constitution of persons as docile institutional subjects because the subject is an effect of knowledge, not a source of knowledge. The disciplines and the confessional work hand in hand to keep alive the fiction of native subjectivities.

3.5 In his genealogy of the shifting political rationalities of State, Foucault reflects on the intimate relations disciplinary and confessional practices gradually establish between individual identity, 'society' and the modern nation State. Foucault observes that a liberal technology of government is accompanied and enabled by the birth of the category 'society', itself born of the 'insights' of the disciplines and the 
confessional and the 'discovery' that society is in a complex relationship of exteriority and interiority to the State. This gives rise to the question of too much government, or at least the idea that 'government adds itself as a supplement which always requires questioning of its necessity and utility' (Foucault, 1981:355). For Foucault, disciplinary interventions were able to spread, within a climate that was constantly suspicious of State intervention, by posing the collectivity of civil society and economy as the measure of a particular technique's acceptability. Within a liberal technology of government it is only possible to have a system of interventions if these do not interfere with the 'natural' processes of society and economy and the free will of the subjects who make it up. Liberalism gives rise to the need to know the limits of human freedom, and deploys of technologies to 'discover' or produce the limits humanity will bear. Liberalism is a 'technology', a method for reflection upon, and criticism of, reality (Foucault, 1981:356). The truths generated about 'society' and 'economy' are gradually enshrined in law, one of multiple regulatory means by which truth governs the population. It is not then that the social sciences stand outside the State, law, and power providing an insight into the manner in which they oppress or empower. Rather the social sciences, by continually problematising and defining the nature of social and economic realities, and the 'rights' of persons within them, embody a liberal technology of government. Although regulation is not in itself bound to have negative effects, the problem Foucault observes with a liberal technology of government is that individuals become important only in relation to the strength of society, the economy and the nation. What one has to do for the state 'is to live, to work, to produce, to consume; and sometimes ... to die' (Foucault, 1988:152). It is a technology of power whose sights are trained on the field of conduct preventing reflection on the means by which power actually operates.

3.6 Foucault's genealogies possess a unique interest in the power of practice, not subjects, to determine the form of discourse. Confessional technologies produce individuality by investing the modern subject with a 'secret soul' unique to itself, which only it can give voice to, albeit in the presence of a suitably qualified expert. The mass of confessional material generated by Western society has been collated, analysed and classified to define what is essential to human beings and groups of human beings, the kinds of 'abnormalities' that coalesce around this essence, as well as the measures required to deal with the new identities and social problems continually being 'discovered'. Disciplinary institutional practices produce individuals by the placement of bodies within controlled, hierarchical spaces, in which each is assigned a meaning in relation to every other and to the overarching norms of productivity and efficiency that govern institutional spaces. Within liberalism, the body of data collected by disciplinary practices gradually suggests to government that it not only has to deal with a territory and its subjects, but 'with a complex and independent reality that has its own laws and mechanisms of reaction, its regulations as well as its possibilities of disturbance' (Foucault, 1984:242). This same 'society' and the individuals that make it up, their privacy, 'security', 'rights' and 'freedoms', then become the name in which an array of measures are implemented to ensure orderly conduct in every domain of life. This points to one of Foucault's central points in The history of sexuality; that the form and nature of society, of the individual and of cultural identity is not a site of resistance to political power, but is the product and means by which politics and enslavement are pursued.

3.7 Foucault calls this mode of action 'bio-technico-power'. Bio power is 'productive' rather than repressive, acting to control and harness bodies, space and time in more efficient, productive and 'biological/natural' directions. It is a mode of power not directed by anyone, but which increasingly enmeshes everyone. Its purpose is the increase of power and order itself, and it regulates in the name of truth and freedom.

Foucault therefore rejects conceptions of power as wielded or possessed by unified political 'interests', concentrated within institutions, over those who do not possess power. He also rejects Heidegger's idea of an inborn 'human' nature, or communicative rationality that stands opposed to power and politics and upon which a politically unbiased view of culture might be authorised. Despite his central concern with institutions, Foucault does not view power as either confined to them or reflective of their specific interests. For Foucault, power can be studied by an analysis of institutions which embody power relations, or in which power relations are reflected, but power relations are not born in or explained by institutions (Foucault, 1982:791). Power operates via the truth about human beings, and what will set them free. To understand what happens in society by theorising political interests is to sidestep more important questions about the institutional and discursive relations that constitute those 'interests'. For Foucault, a research methodology that reads or embeds experience in a theory of social relations cannot provide the epistemological traction required to observe the rise and effects of political interests and modes of social control.

3.8 However, the radical potential Foucault foresaw in the genealogical vantage point does not lie in its ability to provide an 'objective' view. For Foucault there are no epistemological grounds outside the horizon of intelligibility from which to observe culture. The genealogist can never be removed from the field of practice within which meaning emerges, and is shaped by this field of practice. A relativist paradigm must finally admit that the readings offered are contingent, cultural artefacts passing out of time, meaningful only within their context of use. The genealogies described in The history of sexuality, Discipline and punish, 
and Care of the self do not look for the thread that explains the present in a linear telling from past to present (Foucault 1984b:81). Rather, they offer a reading of the condition of the present, informed by contemporary concerns, evidenced in a history of past practices and knowledge relations. Genealogy offers socially relevant descriptions of the interrelations of past practice and knowledge that enable reflection on our current condition. Their value lies in their ability to open the field of practice by throwing current rules into doubt.

3.9 This admission should not be read to suggest that a relativist methodology implies a failure to generalise, or a lack of empirical rigour. To argue that Foucault's relativist sensibility represents a limit to the generalisability of research, and therefore its political usefulness, would be to assume that it is possible to produce positive knowledge about the social world that comes from a place beyond it. But of course, if this were possible, the 'knowledge' produced would make no sense to anyone because it would come from a place inhabited by no one. The argument quickly becomes nonsensical in these terms. Nor does the relative nature of critique imply a lack of empirical rigour. Validity in a Foucaultian frame 'requires patience and a knowledge of details' (Foucault, 1984b:76-77). It 'depends upon a vast accumulation of source material' and a 'relentless erudition' (Foucault, 1984b:76-77). Although the account offered is read through current concerns, and is not in this sense 'objective', it must nevertheless be thoroughly and systematically evidenced. Foucault was not interested in made up stories about the past, but in persuasive, well documented accounts which carry power for our current concerns.

3.10 The genealogical approach involves a study of power that takes in the whole social field within which the objects and subjects reproduced by modernist paradigms emerge and transform. The emergence and transformation of objects and subjects of knowledge are observed in the relations between institutional and cultural practices and changing moral, philosophical and scientific knowledge formations. Deceptively simple, the method involves an observation, 'flat and empirical', of 'what happens' (Foucault, 1983a:217). It is this distance, this reading 'from the outside' that gives Foucault's approach its distinctiveness and by which he sought to provide novel insights into the social condition. While much more might be said about Foucault's genealogical approach and many questions regarding his method remain, it is clear that it emerges from a unique epistemological perspective and aim. The approach does not ask 'what does this knowledge reflect about its producer's intentions or desires' (constructivism), 'what is the cultural meaning of this event or experience for these persons' (social constructionism), or 'what political forces produce and reinforce unequal social relations' (Critical theory). The focus of investigation is not the meaning of individuals, whether given by individual consciousness, cultural perspective or social structure or relations, but a history of practice and the discursive relations to the self they produce.

\section{Research ethics}

4.1 For Foucault, the ethical dilemma of researchers is not how to provide an authentic account of persons or of social events that are not obscured by power, but precisely of resisting claims to have produced knowledge outside the domain of politics and power. Analyses of society that promise to offer authentic, representative and empowering accounts of human beings embody the regulatory aspirations Foucault sought to resist.

4.2 The ethical dangers of representation can perhaps best be exemplified in an example. A grounded theory study of male to female transsexual experience produced by Ekins (1997) may serve this purpose. Following years of participant observation involving one on one interviews, observations and 'saturation' in transsexual culture, Ekins, following a 'grounded theory' methodology, offers an account of 'authentic' transsexual experience. The account is offered as resistance to the biomedical and psychiatric models that pathologise transsexuality. Ekins' text refuses representations of transsexuals as 'sick' or 'abnormal'. Instead he poses a theory of transsexual experience 'grounded' in the experience of transsexuals. He theorises transsexuality as a condition of being born male and proceeding along a line of deeper 'masking' of this maleness, first by dressing up, and finally by changing sex. While the conclusions are rigorously substantiated by the testimony of transsexuals themselves, the text ultimately recirculates meta narrative about natural biological sexuality. That is, maleness is assumed to be a biological inheritance, so that transsexuality becomes a kind of lie covering over a 'deeper' biological truth. In the account, maleness is not cultural, a performance, or a mask in the same sense that transsexuality is. In addition to privileging 'native' performances of 'sexed' behaviour, the account constitutes transsexuals as a group unified in their sexuality, and precisely in the movement from 'real' maleness to 'masked' feminine gender. Transexuality becomes a singular experience, and thereby an identity position, one that crystalises around sexuality. Despite contraindications, the text draws a 'normal' curve of transsexual progression towards femininity, and at the same time underlines the impossibility of transsexuality ever being 'normal' in the way that being born male or female is generally perceived to be. The text disallows seeing transsexual behaviour as part of the natural and as a shifting field of performances, just like other gender subject positions. 
about the centrality of sexuality to identity, and the naturalness or inborn nature of heterosexual reproductive desire and sexual expression. The history of social practices and discourses that constitute 'native sexuality' and its intimate relations with processes of identity formation cannot be revealed within the research interview. This history is as obscure to transsexual persons as to the researcher or anyone else. To assume that transsexual persons, women, migrants, the poor, or other dispossessed or marginalised group is possessed of special insight into their own social condition that might be unearthed by the social scientist is to assume that interview participants and their listeners are somehow beyond the cultural processes that form subjects in general.

4.4 Another example of the ethical dangers of representation is provided by Curthoys and Moore (1995) who aim to valorise the activities of Australian Aborigines by bringing their productive contribution to post European settlement Australia into the light. Curthoys and Moore (1995) seek to contradict the 'racist assumption' that 'Aborigines did not use the land productively' by insisting upon the productive contributions Aborigines made to the colonisation of Australia. The problem is that Aboriginal and Torres Strait Islanders 'have been ignored and thus denied worker status' (Curthoys and Moore, 1995:4). The text aims to bring Aboriginal people into the norm of productive subjectivity and to valorise conduct in relation to its support of the nation. The subjugated knowledge Foucault sought to unearth is not 'buried' within the everyday requiring only a sympathetic listening ear, but knowledge that cannot be heard because it is disqualified by 'the claims of a unitary body of theory which would filter, hierarchise and order them in the name of some true knowledge and some arbitrary idea of what constitutes a science and its objects' (Foucault, 1980:85). Without wishing to imply that there exists a universal and 'authentic' Aboriginality, it might be observed that ways of life made meaningful in relation to land and myth, in which correct conduct bears no relation to productivity, the nation or to an abstract 'society', are silenced by European obsessions with productive, efficient, docile bodies and their support of the collective good.

4.5 The danger for the social sciences Foucault highlights is the reiteration of forms of 'empowerment' and 'rights' that presuppose and reinvest the existing order of rules and regulations. The apparent inevitability of legislated social forms such as kinship units based on heterosexual pair bonding, the nation state, the development of human capital, competitive national market economies, and the tightly regulated institutions designed to support them are the effects of diffuse, anonymous, local, seemingly insignificant practices and normative knowledge. The measure of the effectiveness of the history of disciplinary and confessional practices is the production of a world more and more the same, where spaces of difference are gradually 'liberated' in the name of 'science' and brought into conformity with the dominant social paradigm. . In the examples above, rather than highlight the way transsexuality disrupts assumptions about a natural gender order, the social sciences reinforce prevailing cultural binaries. Histories that reduce Aboriginal contributions to productive labour reinforce the silence around alternative values for ordering life, working to oblige subjects to find freedom in productivity and to regulate their conduct in productive directions.

4.6 To the extent that the social sciences authorise 'authentic needs', and suggest new forms of institutional interventions to serve them, they further reinforce the spread of normative technologies of power. For Foucault, humanity and phenomena are inessential, a wild indeterminacy. The social sciences risk overwriting this inner emptiness or space of possibility and becoming with fixed images of persons and events. In telling us what and how we understand, what oppresses us, and how we may realise ourselves, these methodologies risk participating in processes of social control rather than offering observations about their origins, means and effects. In Foucault's conception, representational social science is not analytic commentary that sits outside the field of power offering neutral or empowering insights about society and culture, but is itself an expression of the operation of power in contemporary society.

4.7 Foucault says that genealogies are 'anti sciences', not in the sense:

that they vindicate a lyrical right to ignorance or non-knowledge: it is not that they are concerned to deny knowledge or that they esteem the virtues of direct cognition and base their practice upon an immediate experience that escapes encapsulation in knowledge. It is not that with which we are concerned. We are concerned, rather, with the insurrection of knowledges that are opposed primarily not to the contents, methods or concepts of a science, but to the effects of the centralising powers which are linked to the institution and functioning of an organised scientific discourse within a society such as ours ... it is really against the effects of the power of a discourse that is considered to be scientific that the genealogy must wage its struggle (Foucault, 1980:84).

In order to open the field of action, scholars must interrogate 'the centralising powers linked to the institution and functioning of an organised scientific discourse' (Foucault, 1980:84).

4.8 This conception of the ethic that underpins research contrasts sharply with traditional modernist approaches to questions of research ethics. Existing conceptions of the purpose or value of research are 
based on a separation of truth and freedom from politics and power such that whatever stands on the side of truth must also necessarily stand for freedom and resistance. This split can take a variety of forms within discussions of research ethics. It occurs within the idea that the integrity of an interview, of the coconstruction of meaning within a given context, is assured when the interviewer reveals a 'personal bias'. 'Resistance' to power will occur, and violence, injustice or scholarly dishonesty will be prevented, by a disclosure of the researcher's personal motivations, interests and social perspective. Such disclosure is seen as necessary to allow the truth of the research participant's 'real' condition, or at least their real experience or interpretation to come through. In other discussions, the focus is on the importance of not betraying the truth of respondents. Questions about who has the power to tell the truth about a life, and over power relations within the research relationship, are central. The assumption is that telling the truth about a life is the best way to avoid questions of power understood as a negative force contained within a relatively static social position. Equality or an absence of power relations are seen to exist when there is negotiation and agreement about the stories produced. A similar code of ethics can be found within institutional research ethics codes which emphasise the consensual agreement of the participant and full disclosure of research aims and requirements prior to interview. Again the view is that power will be overcome when the truth is told, or when there is consensual agreement within full knowledge. The action or effects of knowledge, the reach of knowledge over bodies or fields of action, is not considered because the truth is seen to be emancipating in its very nature.

4.9 A Foucaultian lens insists not so much that existing practices of consent and disclosure are not important, but that they do not in themselves remove researchers from the field of power or from questions of correct ethical conduct. It is precisely in the name of truth, and the opposition of truth to power and politics, that all the 'self-revelations' prompted by the interview and other social research techniques are able to extend their grip over individuals and populations. For this reason Foucault (1984:247) was 'irritated' by analyses of society that promise freedom. For Foucault (1984:245), 'liberty is a practice' which cannot be guaranteed; it must be exercised. Freedom is not something the researcher enables by virtue of the 'deep' insights generated by the research. Nor can it be assured by laws, programs or procedures followed within the research process or arising from the recommendations generated by research. Freedom is always the business of persons acting in specific instances. Positive outcomes or liberation occurs when the intentions of progressive actions coincide with 'the real practice of people in the exercise of their freedom' (1984:246). The potential for change that lies within scholarship arises from its ability to open the field of possible actions, not from its setting new limits and new moral codes that delimit and define the boundaries of action.

4.10 A genealogy of ethics ? of different ways of thinking about the substance, mode of subjection, activity, and telos of ethical conduct - becomes the focus of Foucault's later work. This is undertaken not in order to shed light on the past, or to provide a guide for action in the present, but to allow a perspective on the present, and on the specific problems of the present (Foucault 1983b). Specifically, Foucault comments that his later work revolves around the problem in our time of finding a basis for conduct that is independent of religion, law and science. His commentary on the very different ways in which Europeans have constituted ethical conduct throughout history aims to show that there is no absolute rule that can serve as a guide for conduct. Taken as a whole, his middle and later work might be summarised in a specific concern with the dangers of an ethical mode of action, including governmental action, grounded in truth and science. Ethical research conduct refuses the link between science and conduct. In Foucault's terms, researchers might reject a mode of $d^{\prime}$ 'assujettissement, or way of thinking about the proper conduct of the self, that is premised on a link between ethics and social, economic and political structures (Foucault, 1983b:236). Examples of these links include those commonly made between the apparent good that resides within the responsibility to manage one's productivity and health, the welfare of one's children, spouse, neighbours, and so on, in the name of the national or social good. All such ties between individual conduct and collective well-being, when authorised by social 'scientific' methodologies, become moral laws that oblige persons to follow particular courses of action, or be morally condemned it they refuse.

4.11 In summary, Foucault's work raises a novel perspective on the question of the ethics of research. It implies a need to question a mode of conduct based on an association of knowledge about human beings and society with the social good. For Foucault, the ethical task of the researcher is to resist forms of epistemic authority invested in modernist research practice. Ethical practice centres on an 'indispensable restraint' that 'records the singularity of events outside of any monotonous finality' (Foucault, 1984b:76). Rather than reproduce culture and colonise difference via social analyses that 'empower' others by defining their freedoms, Foucault saw the need for empirical observations of the history of the relations of bodies, practices and knowledge.

4.12 Regardless of where one stands within arguments about the usefulness of different methodological paradigms within social philosophy, Foucault cannot be read through the prisms of constructionist or Critical hermeneutic paradigms without losing the fundamental import of his ideas. Foucault offers a 


\section{Notes}

${ }^{1}$ My interpretation of Foucault's genealogical work is informed by Dreyfus and Rabinow (1983). For related interpretations see Gutting (2005), Mills (2003), Smart (1985), and Kendall and Wickham (1999).

\section{References}

CURTHOYS, A. and Moore, C. (1995) 'Working for the white people: An historiographic essay on Aboriginal and Torres Strait Islander labour', Labour History, No. 69, pp. 1-20.

DENZIN, N. K. (2001) 'The reflexive interview and a performative social science', Qualitative Research, Vol.1, No. 1, pp. 23-46.

DREYFUS, H. L. and Rabinow, P. (1983) Michel Foucault: Beyond structuralism and hermeneutics . Chicago: University of Chicago Press.

EKINS, R. (1997) Male Femaling: A Grounded Approach to Cross-Dressing and Sex-Changing. London: Routledge.

FONTANA, A. (2003) 'Post modern trends in interviewing', in J. Gubrium and J. Holstein (editors) Post modern Interviewing. Thousand Oaks: Sage Publications.

FOUCAULT, M. (1973) The Order of Things: An Archaeology of the Human Sciences. New York: Random House.

FOUCAULT, M. (1976) The history of sexuality volume 1: an introduction . Penguin: London.

FOUCAULT, M. (1977) Discipline and punish: the birth of the prison . London: Penguin.

FOUCAULT, M. (1980) 'Two lectures', in C. Gordon (editor) Power/knowledge: Selected interviews and other writings 1972-1977. New York: Harvester Wheatsheaf.

FOUCAULT, M. (1981) 'History of systems of thought', Philosophy and Social Criticism, Vol. 8, 353-359.

FOUCAULT, M. (1982) 'The subject and power', Critical Enquiry, No. 8, Summer.

FOUCAULT, M. (1983a) 'The subject and power', in H. L. Dreyfus and P. Rabinow (editors) Michel Foucault beyond structuralism and hermeneutics, Second edition. Chicago: University of Chicago Press.

FOUCAULT, M. (1983b) 'On the genealogy of ethics: An overview of work in progress', in H. L. Dreyfus and P. Rabinow (editors) Michel Foucault beyond structuralism and hermeneutics, Second edition . Chicago: University of Chicago Press.

FOUCAULT, M. (1984) 'Space, knowledge, and power', in P. Rabinow (editor) The Foucualt Reader. Penguin: London.

FOUCAULT, M. (1984b) 'Nietzsche, genealogy, history', in P. Rabinow (editor) The Foucualt Reader. London: Penguin.

FOUCAULT, M. (1988) 'Technologies of the self', in L. H. Martin, H. Gutman, and P. H. Hutten (editors) Technologies of the self: A seminar with Michel Foucault . Amherst: The University of Massachusetts Press.

GADAMER, H (1975) Truth and method. London: Sheed and Ward.

GUBRIUM, J. and Holstein, J. (2003) 'From the individual interview to the interviewing society' in J. F. Gubrium and J. A. Holstein (editors) Post modern interviewing. Thousand Oaks: Sage Publications.

GUTTING, G. (2005) The Cambridge companion to Foucault. London: Cambridge University Press.

HABERMAS, J (1984) The theory of communicative action. Boston: Beacon Press.

HEIDEGGER, M. (1967) Being and time. Oxford: Basil Blackwell. 
KENDALL, G and G. M. Wickham (1999), Using Foucault's methods. London, Sage Publications.

MAY, T. (editor) (2002) Qualitative research in action. London: Sage Publications.

MILLS, S (2003) Michel Foucault. London: Routledge.

PORTER, S. (2002) 'Critical realist ethnography', in T. May (editor) Qualitative research in action. London: Sage Publications.

ROSENBLATT, P. C. (2003) 'Interviewing at the border of fact and fiction', in J. F. Gubrium and J. A. Holstein (editors) Post modern interviewing. Thousand Oaks: Sage Publications.

SCHEURICH, J. (1997) Research Method in the Post modern. London: Falmer Press.

SMART, B. (1985) Michel Foucault. London: Routledge.

SMITH, D. (2002) 'Institutional ethnography', in T. May (editor) Qualitative research in action. London: Sage Publications. 